\title{
CONF-9504/2-.49
}

Note: This is a preprint of paper being submitted for publication. Contents of this paper should not be quoted nor referred to without permission of the author(s).

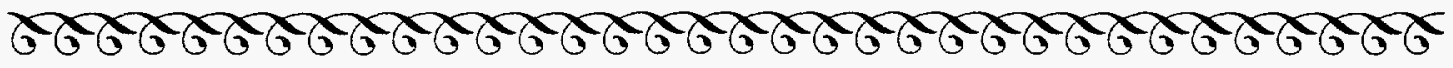

Submitted to Symposium Q: Film Synthesis and Growth Using Energetic Beams

Materials Research Society Meeting

San Francisco Marriott, San Francisco, $C A$

April 17-21, 1995

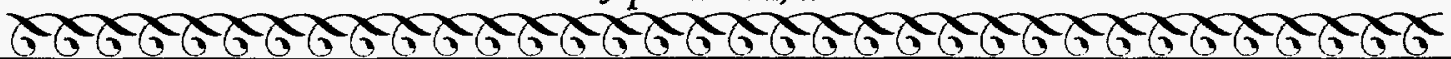

\section{Formation of Artificially-Layered Thin-Film Compounds Using} Pulsed-Laser Deposition

\author{
David P. Norton, B. C. Chakoumakos, D. H. Lowndes, and J. D. Budai
}
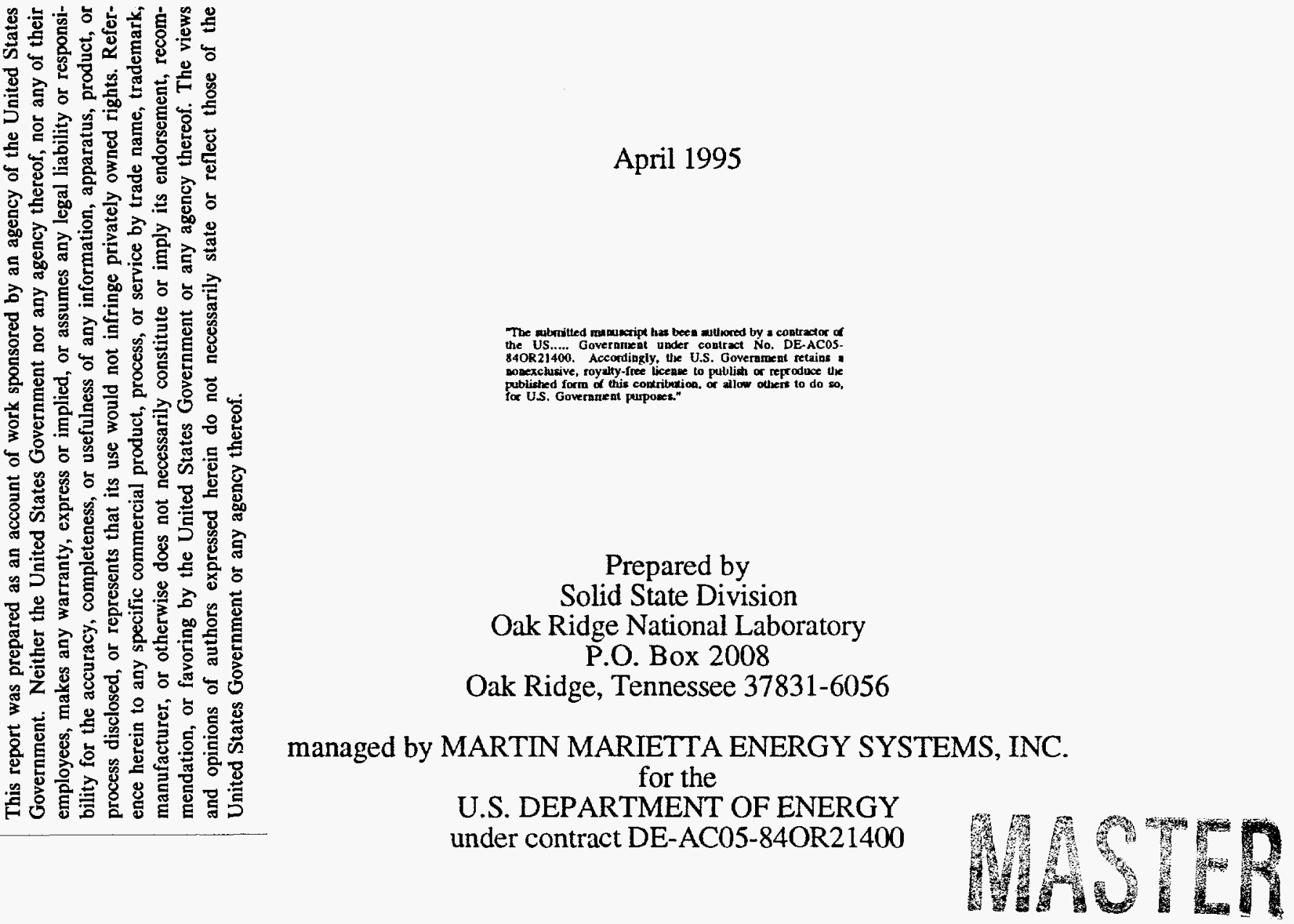


\section{DISCLAIMER}

Portions of this document may be illegible in electronic image products. Images are produced from the best available original document. 


\title{
FORMATION OF ARTIFICIALLY-LAYERED THIN-FILM COMPOUNDS USING PULSED-LASER DEPOSITION
}

DAVID P. NORTON, B. C. CHAKOUMAKOS, D. H. LOWNDES, AND J. D. BUDAI Oak Ridge National Laboratory, P. O. Box 2008, Oak Ridge, TN 37831-6056

\begin{abstract}
Superlattice structures, consisting of $\mathrm{SrCuO}_{2},(\mathrm{Sr}, \mathrm{Ca}) \mathrm{CuO}_{2}$, and $\mathrm{BaCuO}_{2}$ layers in the tetragonal, "infinite layer" crystal structure, have been grown by pulsed-laser deposition (PLD). Superlattice chemical modulation is observed for structures with component layers as thin as a single unit cell $(-3.4 \AA)$, indicating that unit-cell control of $(\mathrm{Sr}, \mathrm{Ca}) \mathrm{CuO}_{2}$ growth is possible using conventional pulsed-laser deposition over a wide oxygen pressure regime. X-ray diffraction intensity oscillations, due to the finite thickness of the film, indicate that these films are extremely flat with a thickness variation of only $\sim 20 \AA$ over a length scale of several thousand angstroms. Using the constraint of epitaxy to grow metastable cuprates in the infinite layer structure, novel high-temperature superconducting structural families have been formed. In particular, epitaxiallystabilized $\mathrm{SrCuO}_{2} / \mathrm{BaCuO}_{2}$ superlattices, grown by sequentially depositing on lattice-matched (100) $\mathrm{SrTiO}_{3}$ from $\mathrm{BaCuO}_{2}$ and $\mathrm{SrCuO}_{2}$ ablation targets in a PLD system, show metallic conductivity and superconductivity at $T_{c}$ (onset) $\sim 70 \mathrm{~K}$. These results show that pulsed-laser deposition and epitaxial stabilization have been used to effectively "engineer" artificially-layered thin-film materials.
\end{abstract}

\section{INTRODUCTION}

Since the discovery of the high-temperature superconductivity (HTSc), ${ }^{1}$ intensive efforts have revealed numerous families of layered crystal structures containing copper oxide layers, ${ }^{2}$ with superconducting transition temperatures as high as $135 \mathrm{~K}$ for the $\mathrm{Hg}$-containing cuprates. ${ }^{3}$ Typically, bulk synthesis techniques have been the primary tool in the search for new HTSc materials. Recently, high-pressure synthesis methods have played a prominent role to make metastable cuprate phases. ${ }^{4-7}$ However, thin-film growth methods offer unique advantages for the atomic engineering of new HTSc materials through the ability to form artificially layered crystal structures. Moreover, the surfaces of single-crystal substrates provide an "atomic template" that can be used to stabilize epitaxial films in metastable crystal structures. Advances in the understanding of epitaxial thin-film growth of the cuprates have heightened interest in the possibility of creating artificially layered materials. $8-10$ The cuprate superconductors are ideal candidates to work on, because their crystal structures are composed of chemically distinct layer modules, most important of which is the square $\mathrm{CuO}_{2}$ layer.

A prelude to the formation of artificially-layered cuprates has been the epitaxial stabilization of infinite layer $(\mathrm{Ca}, \mathrm{Sr}) \mathrm{CuO}_{2}$ single-crystal thin films. ${ }^{11-14}$ The infinite layer $(\mathrm{Ca}, \mathrm{Sr}) \mathrm{CuO}_{2}$ structure type, consisting of square $\mathrm{CuO}_{2}$ layers alternately stacked with square layers of alkaline earth atoms, is the simplest cuprate with the essential structural features for HTSc. 15 Indeed, the infinite-layer structure can be viewed as a fundamental building unit of all of the HTSc cuprates. Bulk synthesis of $(\mathrm{Ca}, \mathrm{Sr}) \mathrm{CuO}_{2}$ with the tetragonal, "infinite layer" structure generally requires the use of high pressure and high temperature bulk processing techniques. $19-24$ However, recent experiments show that this metastable compound can be epitaxially stabilized at less than atmospheric pressure, resulting in the growth of tetragonal $(\mathrm{Ca}, \mathrm{Sr}) \mathrm{CuO}_{2}$ single crystal thin films of the infinite layer defect perovskite structure by pulsed-laser deposition (PLD) over a wide range of growth conditions. ${ }^{6-17}$ However, in order to synthesize artificially-layered HTSc structures, the growth of $(\mathrm{Ca}, \mathrm{Sr}) \mathrm{CuO}_{2}$ must be controlled at the unit-cell level $(-3.4 \AA)$.

In this paper, we show that unit-cell control of $(\mathrm{Ca}, \mathrm{Sr}) \mathrm{CuO}_{2}$ film growth is possible using conventional PLD. We have successfully grown $\mathrm{SrCuO}_{2} /(\mathrm{Ca}, \mathrm{Sr}) \mathrm{CuO} 2$ superlattice structures utilizing a PLD multi-target system operating at an oxygen pressure of $200 \mathrm{~m}$ Torr. X-ray 
diffraction peaks attributed to the superlattice structures are observed, even for $\mathrm{SrCuO}_{2} /(\mathrm{Ca}, \mathrm{Sr}) \mathrm{CuO}_{2}$ superlattice structures with $\mathrm{SrCuO}_{2}$ and $(\mathrm{Ca}, \mathrm{Sr}) \mathrm{CuO}_{2}$ layer thicknesses of a single unit cell $(-3.4 \AA)$. The $\mathrm{x}$-ray diffraction data also reveal finite-thickness oscillations in the $\mathrm{x}$ ray intensity, which is indicative of films with extremely flat surfaces. The growth of superlattice structures by PLD is made possible, in large part, by this surface flatness. In addition, we also report the synthesis of novel artificially-layered HTSc compounds, grown as $\mathrm{SrCuO}_{2} / \mathrm{BaCuO}_{2}$ crystalline superlattice structures. In showing that the growth of infinite layer materials in superlattice structures can be controlled on the unit cell scale using conventional PLD with no in situ surface monitoring, this work offers the exciting possibility of greatly broadening the conditions under which new artificially-layered HTSc phases can be formed.

\section{EXPERIMENTAL CONDITIONS}

The films were grown on (100) $\mathrm{SrTiO}_{3}$ substrates utilizing conventional multi-target PLD. Polycrystalline, orthorhombic $(\mathrm{Ca}, \mathrm{Sr}) \mathrm{CuO}_{2}$ and cubic $\mathrm{BaCuO}_{2}$ ablation targets were mounted in a multi-target carousel. The $(\mathrm{Ca}, \mathrm{Sr}) \mathrm{CuO}_{2}$ targets were made by solid state reaction of high-purity $\mathrm{SrCO}_{3}, \mathrm{CaCO}_{3}$, and $\mathrm{CuO}$ which were pressed and fired at $1025^{\circ} \mathrm{C}$. Powder $\mathrm{x}$-ray diffraction confirmed complete decomposition of the carbonates. The $\mathrm{BaCuO}_{2}$ target was prepared using high-purity $\mathrm{BaCuO}_{2}$ powder. (100) $\mathrm{SrTiO}_{3}$ substrates were cleaned with solvents prior to being mounted with silver paint on the substrate heater. The KrF excimer laser ablation beam was focused to a $1 \mathrm{~cm}$ horizontal line and vertically scanned over the rotating targets to improve film thickness uniformity. The focused laser energy density was approximately $2 \mathrm{~J} / \mathrm{cm}^{2}$, and the substrates, heated to $500-625^{\circ} \mathrm{C}$, were placed $10 \mathrm{~cm}$ from the ablation targets. Film growth was carried out in 200 mTorr of oxygen. Before growing the $\mathrm{SrCuO}_{2} / \mathrm{BaCuO}_{2}$ layered structures, a $9.0 \mathrm{~nm}$ thick $\mathrm{SrCuO}_{2}$ buffer layer was grown to initiate epitaxial growth of the infinite layer structure on the $\mathrm{SrTiO}_{3}$ surface. Total film thickness varied from 90 to $120 \mathrm{~nm}$, corresponding to 60 or more superlattice periods. After deposition, the films were cooled at $\sim 80^{\circ} \mathrm{C} / \mathrm{min}$ in 200 mTorr of oxygen, with the pressure increased to 760 Torr at $375^{\circ} \mathrm{C}$ for the $\mathrm{SrCuO}_{2} / \mathrm{BaCuO}_{2}$ superlattices. The structure and epitaxy of the films were investigated by $\mathrm{x}$-ray scattering measurements obtained using both two-circle and four-circle diffractometers with monochromated $\mathrm{CuK} \alpha \mathrm{x}$-ray sources. In addition, more sensitive synchrotron $\mathrm{x}$-ray measurements were obtained for one film using beamline X14 at the National Synchrotron Light Source (NSLS) operating with a $\mathrm{Si}(111)$ monochromator and a $\mathrm{Ge}(111)$ analyzer set near the $\mathrm{CuK} \alpha$ wavelength.

\section{$\mathrm{SrCuO}_{2} /(\mathrm{Ca}, \mathrm{Sr}) \mathrm{CuO}_{2}$ SUPERLATTICES}

The growth of superlattice structures by PLD requires a well-calibrated and controlled growth rate. Initial estimates of the film thickness per laser shot were obtained by growing singlecomponent $(\mathrm{Ca}, \mathrm{Sr}) \mathrm{CuO}_{2}$ films and measuring their thickness. However, for superlattice growth, the growth rate and/or sticking coefficient of each component layer can deviate from the values obtained from single-component film growth. For instance, growth of a single unit cell of $\mathrm{SrCuO}_{2}$ on a $\mathrm{Sr}_{0.2} \mathrm{Ca}_{0.8} \mathrm{CuO}_{2}$ surface involves slightly different surface chemistry than growth on $\mathrm{SrCuO}_{2}$, and can lead to a different growth rate. Thus, the final growth rate calibration was obtained from the superlattice satellite peak locations in the x-ray diffraction data.

For $\mathrm{SrCuO}_{2} /(\mathrm{Ca}, \mathrm{Sr}) \mathrm{CuO}_{2}$ superlattices with the infinite layer crystal structure, the $\mathrm{x}$-ray diffraction data should show the infinite layer $(00 \mathrm{l})$ peaks, along with superlattice satellite peaks due to the additional chemical modulation from the superlattice structure. The nomenclature used to describe the nominal superlattice structure is $\mathrm{M} \times \mathrm{N}$, where $\mathrm{M}$ is the number of unit cells of the first component, and $\mathrm{N}$ is the number of unit cells of the second component. Figure 1 shows the $x$-ray diffraction pattern, obtained using a rotating anode $x$-ray source, for a $2 \times 1$ $\mathrm{SrCuO}_{2} / \mathrm{Sr}_{0.2} \mathrm{Ca}_{0.8} \mathrm{CuO}_{2}$ superlattice structure with 80 periods grown at $600^{\circ} \mathrm{C}$. The pattern shows peaks due to both the infinite layer crystal structure as well as to the superlattice $\mathrm{Sr} / \mathrm{Ca}$ chemical modulation. Based on the location of the superlattice peaks, the superlattice chemical periodicity is $9.28 \AA$. The fundamental peaks yield an average lattice parameter of $\mathrm{c} \sim 3.38 \AA$. $\mathrm{A}$ rocking curve through the infinite layer $(002)$ reflection for this film yields a mosaic FWHM of $\sim 0.11^{\circ}$, an indication of the high degree of alignment. 


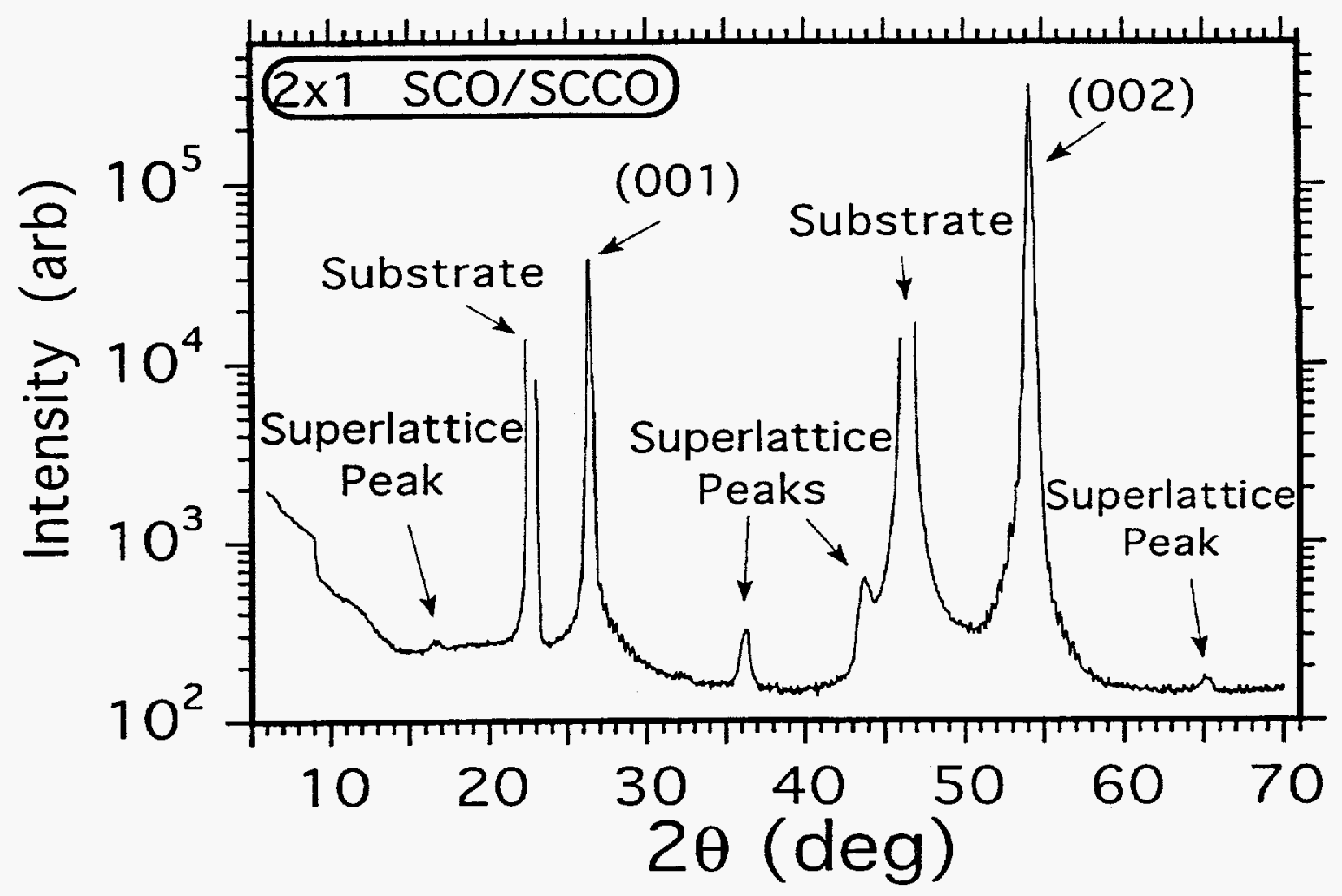

Fig. $1 \mathrm{X}$-ray diffraction (Cu K $\alpha$ radiation) data for a $2 \times 1 \mathrm{SrCuO}_{2} / \mathrm{Sr}_{0.2} \mathrm{Ca}_{0.8} \mathrm{CuO}_{2}(\mathrm{SCO} / \mathrm{SCCO})$ superlattice showing diffraction peaks due to the $\mathrm{Sr} / \mathrm{Ca}$ chemical modulation of the superlattice thin-film structure. From the superlattice peak locations, the superlattice period is 9.28

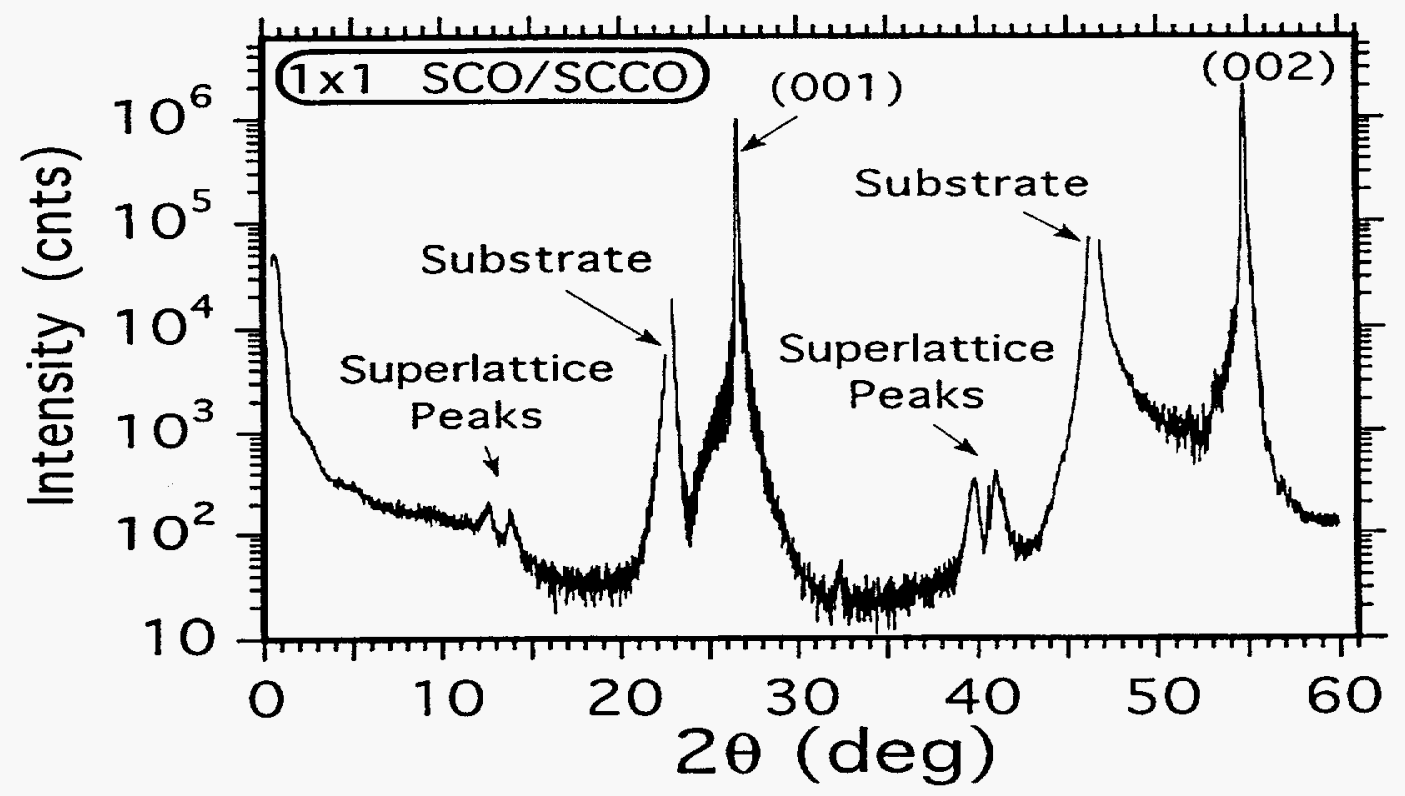

Fig. $2 \mathrm{X}$-ray diffraction data for a $1 \times 1 \mathrm{SrCuO}_{2} / \mathrm{Sr}_{0 .} \mathrm{Ca}_{0.8} \mathrm{CuO}_{2}(\mathrm{SCO} / \mathrm{SCCO})$ superlattice showing diffraction peaks due to the $\mathrm{Sr} / \mathrm{Ca}$ chemical modulation of the superlattice thin-film structure. The superlattice peaks are split due to the fact that the chemical periodicity is slightly incommensurate with the "infinite layer" structural periodicity. From the superlattice peak locations, the superlattice period is $7.0 \mathrm{~A}$. 
Figure 2 shows the $\mathrm{x}$-ray diffraction pattern for a $1 \times 1 \mathrm{SrCuO}_{2} / \mathrm{Sr}_{0.2} \mathrm{Ca}_{0.8} \mathrm{CuO}_{2}$ superlattice. Even for this structure, with $\mathrm{SrCuO}_{2}$ and $\mathrm{Sr}_{0.2} \mathrm{Ca}_{0.8} \mathrm{CuO}_{2}$ layers only 1 unit cell thick, $\mathrm{x}$-ray diffraction peaks attributed to the superlattice are observed indicating control of the film growth at the infinite layer unit cell level of $-3.4 \AA$. The superlattice modulation periodicity for the $1 \times 1$ structure is $7.0 \AA$ and the average lattice parameter is $c \sim 3.35 \AA$. For $\mathrm{SrCuO}_{2}$ and $\mathrm{Sr}_{0.2} \mathrm{Ca}_{0.8} \mathrm{CuO}_{2}$, the nominal ideal lattice constants are 3.45 and $3.25 \AA$, respectively. Thus, for both the $1 \times 1$ and $2 \times 1 \mathrm{SrCuO}_{2} / \mathrm{Ca}_{0.8} \mathrm{Sr}_{0.2} \mathrm{CuO}_{2}$ structures, the chemical modulation periodicities are within $8 \%$ of that for the nominal structure. In addition, the average c-axis lattice parameters are in excellent agreement with the values 12 for the infinite layer films with the same average stoichiometries.

The quality of the superlattice structures is sensitive to the growth temperature as shown by $x$-ray diffraction. While $4 \times 4 \mathrm{SrCuO}_{2} / \mathrm{Sr}_{0.2} \mathrm{Ca}_{0.8} \mathrm{CuO}_{2}$ superlattices grown at 500 and $600^{\circ} \mathrm{C}$ had superlattice peaks that are similar in both intensity and width, the $2 \times 2,2 \times 1$, and $1 \times 1$ $\mathrm{SrCuO}_{2} / \mathrm{Sr}_{0.2} \mathrm{Ca}_{0.8} \mathrm{CuO}_{2}$ superlattice structures grown at $500^{\circ} \mathrm{C}$ had superlattice peaks significantly lower in intensity and broader than for similar structures grown at $600^{\circ} \mathrm{C}$. This suggests that the growing surface is significantly smoother at $600^{\circ} \mathrm{C}$ than at $500^{\circ} \mathrm{C}$ due to increased surface diffusion. In addition, this result indicates that bulk interdiffusion is not a significant factor at temperatures up to $600^{\circ} \mathrm{C}$, as interdiffusion of the layers would tend to make the diffraction peaks broader and lower in intensity at the higher temperature.

It is interesting that superlattice structures with component layer thicknesses as small as $3.3 \AA$ can be obtained with a relatively simple thin-film growth system which has no in situ surface analysis capability. This result implies that the growing surface of the infinite layer films must be quite smooth, on a near-atomic scale. A direct measure of this surface smoothness is given in the X-ray diffraction pattern of the $1 \times 1 \mathrm{SrCuO}_{2} / \mathrm{Sr}_{0.2} \mathrm{Ca}_{0.8} \mathrm{CuO}_{2}$ superlattice. Figure 3 shows an expanded plot about the (001) infinite layer peak, which shows oscillations in the x-ray diffraction intensity due to the finite film thickness. Finite thickness oscillations are observed only if the film surface is flat over a length scale on the order of the coherence length of the $x$-ray source. For these synchrotron measurements, the coherence length is at least of the order of thousands of angstroms. Over 30 oscillations are present on each side of the (001) peak, giving a fractional

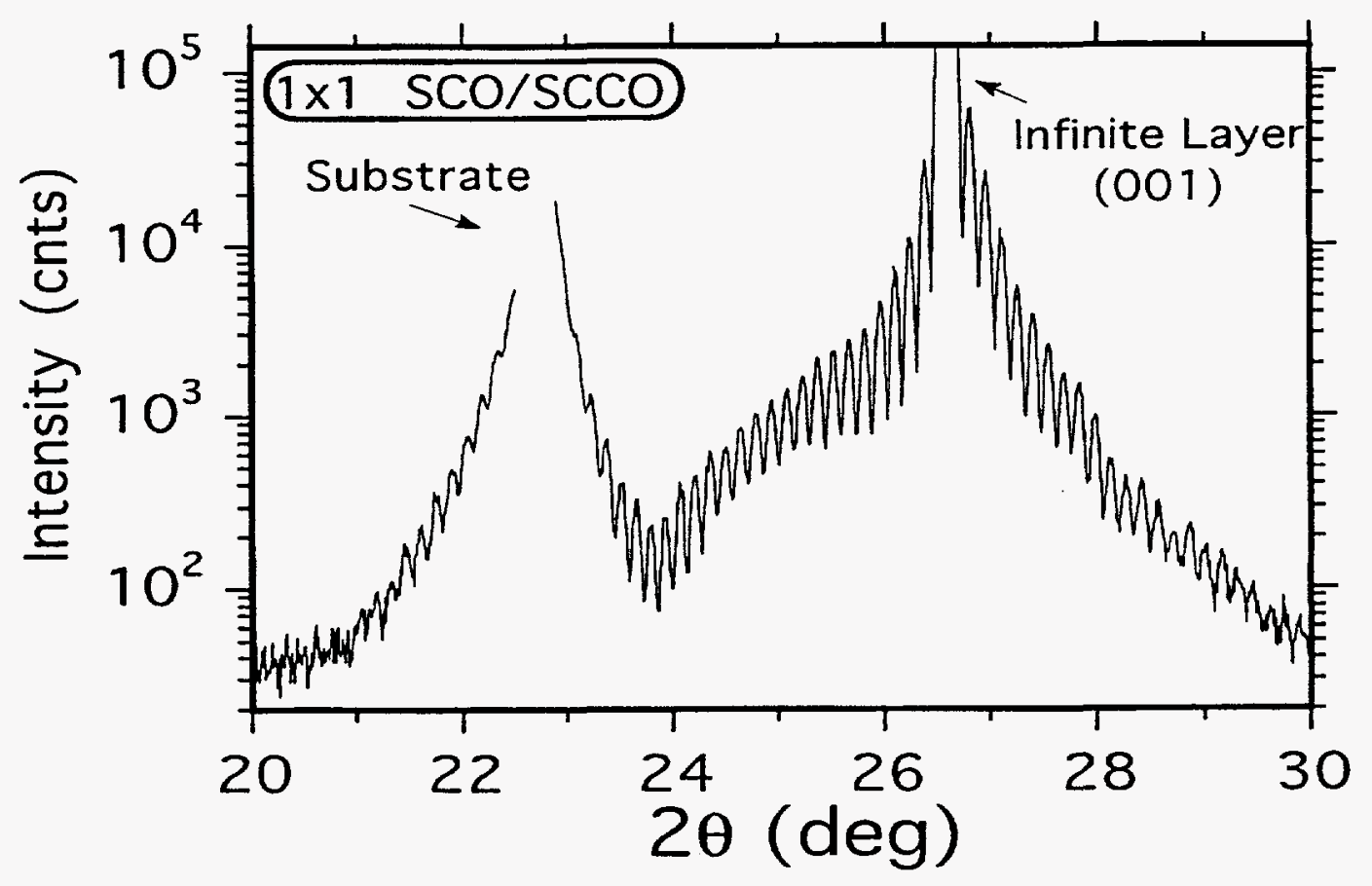

Fig. $3 \mathrm{X}$-ray diffraction data for a $1 \times 1 \mathrm{SrCuO}_{2} / \mathrm{Sr}_{0.2} \mathrm{Ca}_{0.8} \mathrm{CuO}_{2}(\mathrm{SCO} / \mathrm{SCCO})$ superlattice about the (001) "infinite layer" peak showing X-ray intensity oscillations due to the finite thickness of the film. The number of resolvable oscillations suggests that the film thickness varies by only $20 \AA$ over a length scale of several thousand angstroms. 
variation of film thickness relative to the total film thickness of $1 / 30$, which yields a thickness variation of only $20 \AA$ over thousands of angstroms. 25 This is on the order of the expected substrate surface roughness, and indicates that these infinite layer films are extremely flat under the growth conditions utilized.

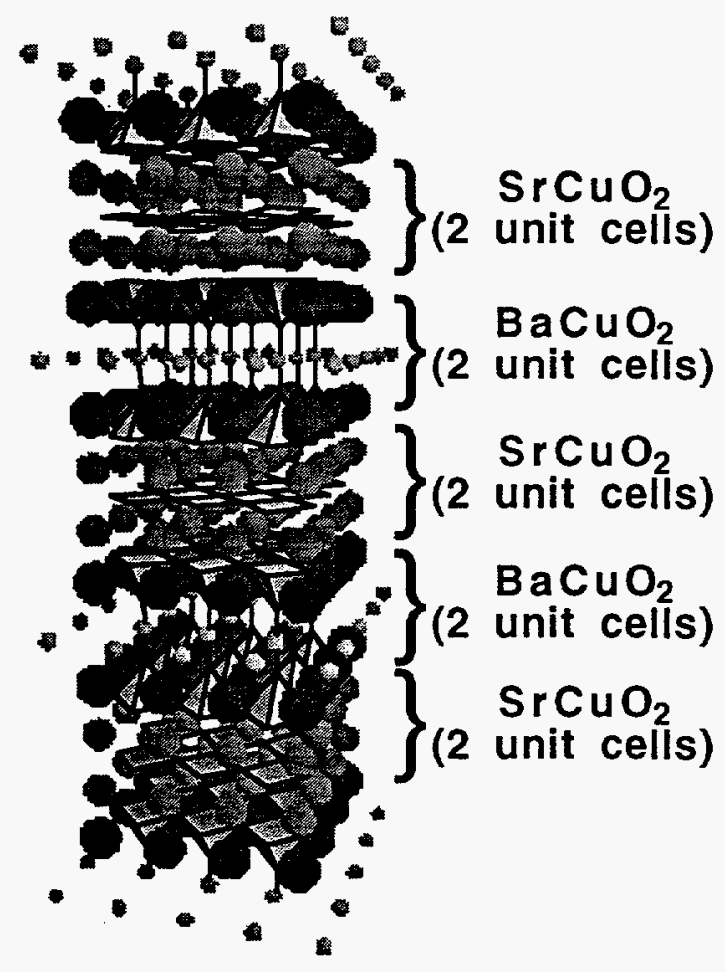

Fig. 4 Structural model of a $2 \times 2 \mathrm{SrCuO}_{2} / \mathrm{BaCuO}_{2}$ superlattice compound, also designated as $\mathrm{Ba}_{2} \mathrm{Sr}_{2} \mathrm{Cu}_{4} \mathrm{O}_{8+\delta}$. The $\mathrm{Ba}, \mathrm{Sr}$, and $\mathrm{Cu}$ atoms are represented by the large, medium, and small spheres, respectively. The $\mathrm{CuO}_{4}$ and $\mathrm{CuO}_{5}$ units are shown as shaded polyhedra.

Typically, the room temperature resisitivity for these superlattices was $1-10 \mathrm{~m} \Omega-\mathrm{cm}$. Superconductivity was observed only for superlattice structures grown at $\mathrm{T} \geq 525^{\circ} \mathrm{C}$. Figure 5 shows the resistivity for $2 \times 2 \mathrm{SrCuO}_{2} / \mathrm{BaCuO}_{2}$ superlattices grown at various temperatures. Although $T_{c}$ increases with increasing growth temperature up to $600^{\circ} \mathrm{C}$, structures grown at higher temperatures contain significant amounts of cubic $\mathrm{BaCuO}_{2}$ as an impurity phase.

The x-ray diffraction pattern for a $1 \times 2 \mathrm{SrCuO}_{2} / \mathrm{BaCuO}_{2}$ superlattice is shown in Fig. 6 , along with the corresponding schematic of the ideal atomic arrangement. The solid arrows indicate diffraction peaks from the artificially-layered compounds, while the asterisks designate peaks from the $\mathrm{SrCuO}_{2}$ buffer layer. The vertical dashed lines show the expected locations of the (00l) peaks for the ideal artificially-layered structure. The diffraction pattern clearly indicates the presence of mulitlayer modulation along the c-axis. While the diffraction peaks are close to the ideal (00R) locations, some of the peak intensities are weaker than that predicted from structure calculations with slight deviations or splitting of some of the peaks about the expected peak locations. The most consistent interpretation of these diffraction patterns is to view the peaks as originating either 


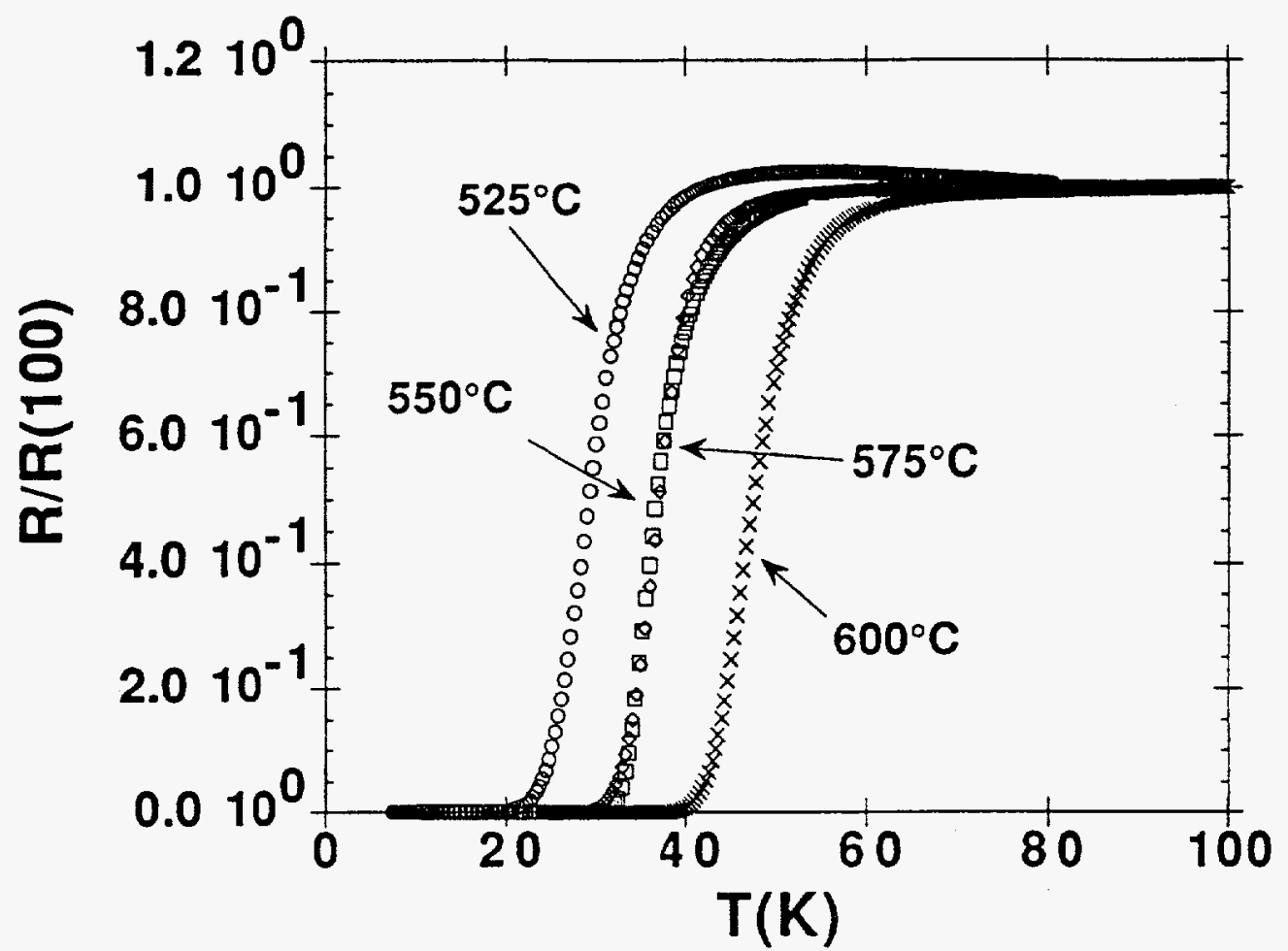

Fig. 5 Normalized resistance plotted as a function of temperature for $2 \times 2 \mathrm{SrCuO}_{2} / \mathrm{BaCuO}_{2}$ superlattices grown at various temperatures.

from the structural modulation or from the superlattice chemical modulation. The structural modulation arises from the crystallinity of the compound. It represents, for instance, the average cation spacing along the c-axis (the growth direction), with some structure peaks present even with no $\mathrm{Ba} / \mathrm{Sr}$ chemical modulation. For instance, the (003) and (006) peaks for $\mathrm{Ba}_{2} \mathrm{SrCu}_{3} \mathrm{O}_{6+\delta} \delta$ would be present for an infinite layer alloy film with no $\mathrm{Ba} / \mathrm{Sr}$ ordering along the c-axis. Only as $\mathrm{Ba} / \mathrm{Sr}$ ordering is realized are other $(00 \mathrm{l})$ structure peaks expected. If the $\mathrm{Ba} / \mathrm{Sr}$ chemical modulation is slightly incommensurate with the structural modulation, superlattice satellite peaks will be present on either side of strong structural peaks at positions which deviate from the ideal (00R) locations. Peaks from the structural and chemical periodicities converge if the deposition process yields exactly integral numbers of $\mathrm{SrCuO}_{2}$ and $\mathrm{BaCuO}_{2}$ infinite layer unit cells per multilayer period. The deviations observed in the peak locations indicate that the chemical modulation is slightly incommensurate with the structural modulation. The fact that the peak intensities are somewhat weaker than expected indicates the presence of $\mathrm{Ba} / \mathrm{Sr}$ disorder. Since these thin films were formed as artificially-layered superlattices by sequentially depositing $\mathrm{SrCuO}_{2}$ and $\mathrm{BaCuO}_{2}$ layers, it is reasonable to assume that much of this disorder originates from substrate surface roughness and slight inaccuracies in the deposition rates. The $\mathrm{x}$-ray diffraction pattern gives a c-axis lattice constant for the structural periodicity of $12.1 \AA$, while the chemical periodicity for the same structure is $14.0 \AA$. Four-circle $\mathrm{x}$-ray diffraction data show these structures to be tetragonal with in-plane lattice constants of $3.9 \AA$, thus matching the lattice constant for the $\mathrm{SrTiO}_{3}$ substrates.

In these artificially-layered structures, the $\mathrm{SrCuO}_{2}$ and $\mathrm{BaCuO}_{2}$ sub-units could have the ideal infinite layer structure consisting of four-fold coordinated $\mathrm{CuO}_{2}$ planes separated by oxygenfree alkaline earth ( $\mathrm{Sr}$ or $\mathrm{Ba}$ ) layers, with no apical oxygen for any of the copper atoms. However, this seems unlikely as all of the hole-doped superconductors have apical oxygen on at least some of the copper atoms, and thermoelectric power measurements indicate that these materials are hole conductors. ${ }^{19}$ The more reasonable possibility is for the Ba planes to contain some oxygen thus creating apical oxygen and increasing the $\mathrm{Cu}$ coordination. The schematics of the 

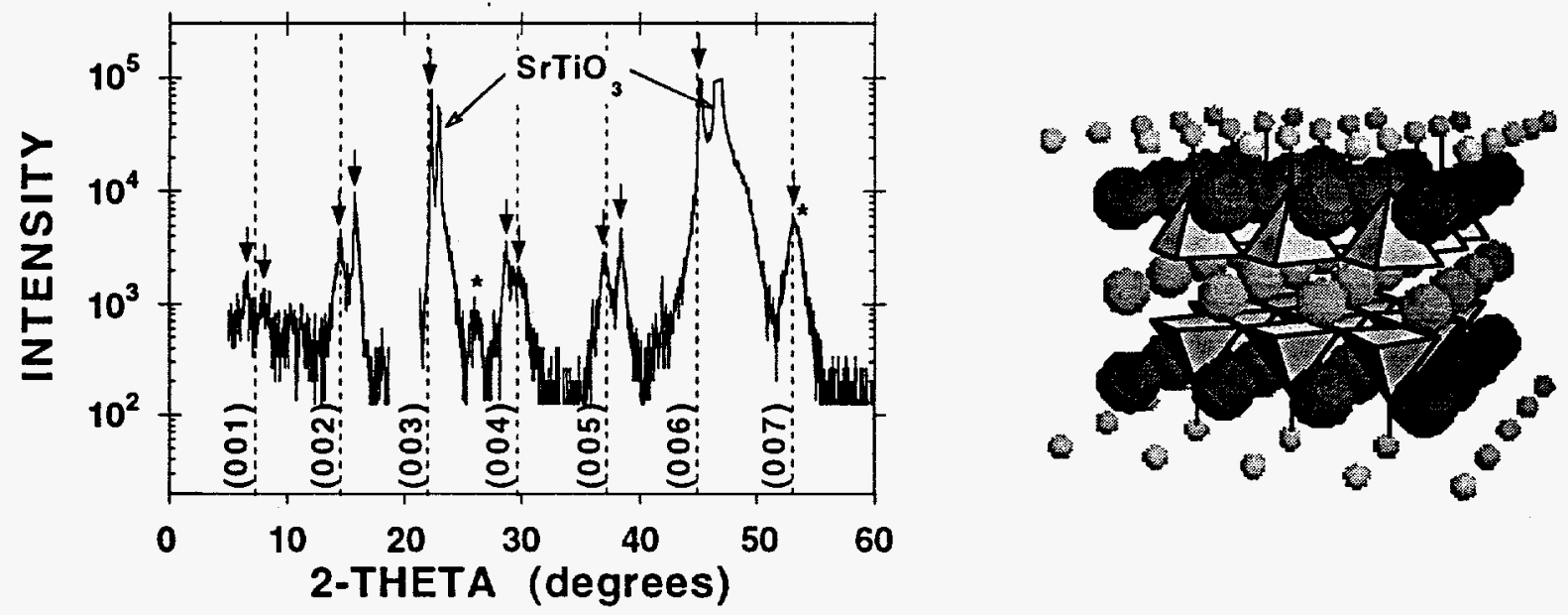

Fig. $6 \mathrm{X}$-ray diffraction patterns ( $\mathrm{Cu} \mathrm{K} \alpha$ radiation) and structural model for the $n=2$ member of the $\mathrm{Ba}_{2} \mathrm{Sr}_{n-1} \mathrm{Cu}_{n+1} \mathrm{O}_{2 n+2+\delta}$ series. The dashed lines indicate the nominal locations of the (00R) peaks, while the solid arrows indicate diffraction peaks due to the artificially-layered structures. In the model, the $\mathrm{Ba}, \mathrm{Sr}$, and $\mathrm{Cu}$ atoms are represented by the large, medium, and small spheres, respectively, and the $\mathrm{CuO}_{4}$ and $\mathrm{CuO}_{5}$ units as shaded polyhedra.

$\mathrm{Ba}_{2} \mathrm{Sr}_{n-1} \mathrm{Cu}_{1+n} \mathrm{O}_{2 n+2+\delta}$ structures shown in Figs. 4 and 6 assume this to be true. It is not clear, however, whether oxygen on the $\mathrm{Ba}$ planes resides there at the expense of oxygen on specific $\mathrm{Cu}$ planes. Because of this uncertainty, we have designated the materials as $\mathrm{Ba}_{2} \mathrm{Sr}_{n-1} \mathrm{Cu}_{n+1} \mathrm{O}_{2 n+2+\delta}$ which makes no inference as to whether inequivalent $\mathrm{Cu}$ sites are present, although this may occur.

Figure 7 shows the resistivity for the $n=2,3$, and 4 members of $\mathrm{Ba}_{2} \mathrm{Sr}_{n-1} \mathrm{Cu}_{n+1} \mathrm{O}_{2 n+2+\delta}$. The room-temperature resistivities are $1-5 \mathrm{~m} \Omega-\mathrm{cm}$. The $n=2$ member has the highest superconducting transition temperature with $T_{c}$ (onset) $=70 \mathrm{~K}$ and $T_{c}(\mathrm{R}=0)=50 \mathrm{~K}$. The $n=3$ member has $T_{c}$ (onset) $=60 \mathrm{~K}, T_{c}(\mathrm{R}=0)=40 \mathrm{~K}$, and the $n=4$ member has $T_{c}$ (onset) $=40 \mathrm{~K}$ and $T_{c}(\mathrm{R}=0)=$ $20 \mathrm{~K}$. The measurement current density used was $\sim 50 \mathrm{~A} / \mathrm{cm}^{2}$. Note that for these artificiallylayered compounds, $T_{c}$ decreases as $n$ increases. This behavior differs from that observed for other HTSc series, in which $T_{c}$ increases as $n$ increases. One possible explanation is that these $\mathrm{Ba}_{2} \mathrm{Sr}_{n-1} \mathrm{Cu}_{n+1} \mathrm{O}_{2 n+2+\delta}$ films are not optimally doped, with an increase in $T_{c}$ possible with an increase or reduction in the hole carrier density. Another possibility is that the use of $\mathrm{Sr}$ to separate the $\mathrm{CuO}_{2}$ planes inhibits the transfer of charge from the $\mathrm{Ba}_{2} \mathrm{Cu}_{2} \mathrm{O}_{4}$ layer into the $\mathrm{SrCuO}_{2}$ layers. This latter scenario would mean that the superconducting transitions observed for all of these structures is due only to the $\mathrm{Ba}_{2} \mathrm{Cu}_{2} \mathrm{O}_{4}$ layers, with little or no coupling into the $\mathrm{CuO}_{2}$ planes adjacent to the $\mathrm{Sr}$ atoms. In fact, this interpretation is consistent with the observed behavior for $\mathrm{YBa}_{2} \mathrm{Cu}_{3} \mathrm{O}_{7} / \mathrm{PrBa}_{2} \mathrm{Cu}_{3} \mathrm{O}_{7}$ superlattices, where $T_{c}$ decreases as the nonsuperconducting $\mathrm{PrBa}_{2} \mathrm{Cu}_{3} \mathrm{O}_{7}$ layer thickness increases. It also suggests that replacing $\mathrm{Sr}$ with $\mathrm{Ca}$ may increase charge transfer into adjacent $\mathrm{CuO}_{2}$ planes and increase $T_{c}$. Unfortunately, the formation of high-quality $\mathrm{CaCuO}_{2} / \mathrm{BaCuO}_{2}$ superlattices is more difficult due to the ionic radii differences for $\mathrm{Ba}$ and $\mathrm{Ca}$.

\section{$\mathrm{SrTiO}_{3} / \mathrm{BaCuO}_{2}$ SUPERLATTICES}

We have also investigated the epitaxially stabilization of infinite layer $\mathrm{BaCuO}_{2}$ using perovskite-like materials other than $\mathrm{SrCuO}_{2}$ in a superlattice structure. Figure 8 shows the $\mathrm{x}$-ray diffraction pattern for a $\mathrm{BaCuO}_{2} / \mathrm{SrTiO}_{3}$ superlattice with a superlattice period of $20.4 \AA$. The strongest diffraction peaks correspond to structure peaks with an average d-spacing of $4.1 \AA$, which is consistent with the formation of $\mathrm{a} \mathrm{BaCuO}_{2} / \mathrm{SrTiO}_{3}$ superlattice with the $\mathrm{BaCuO}_{2}$ layers 


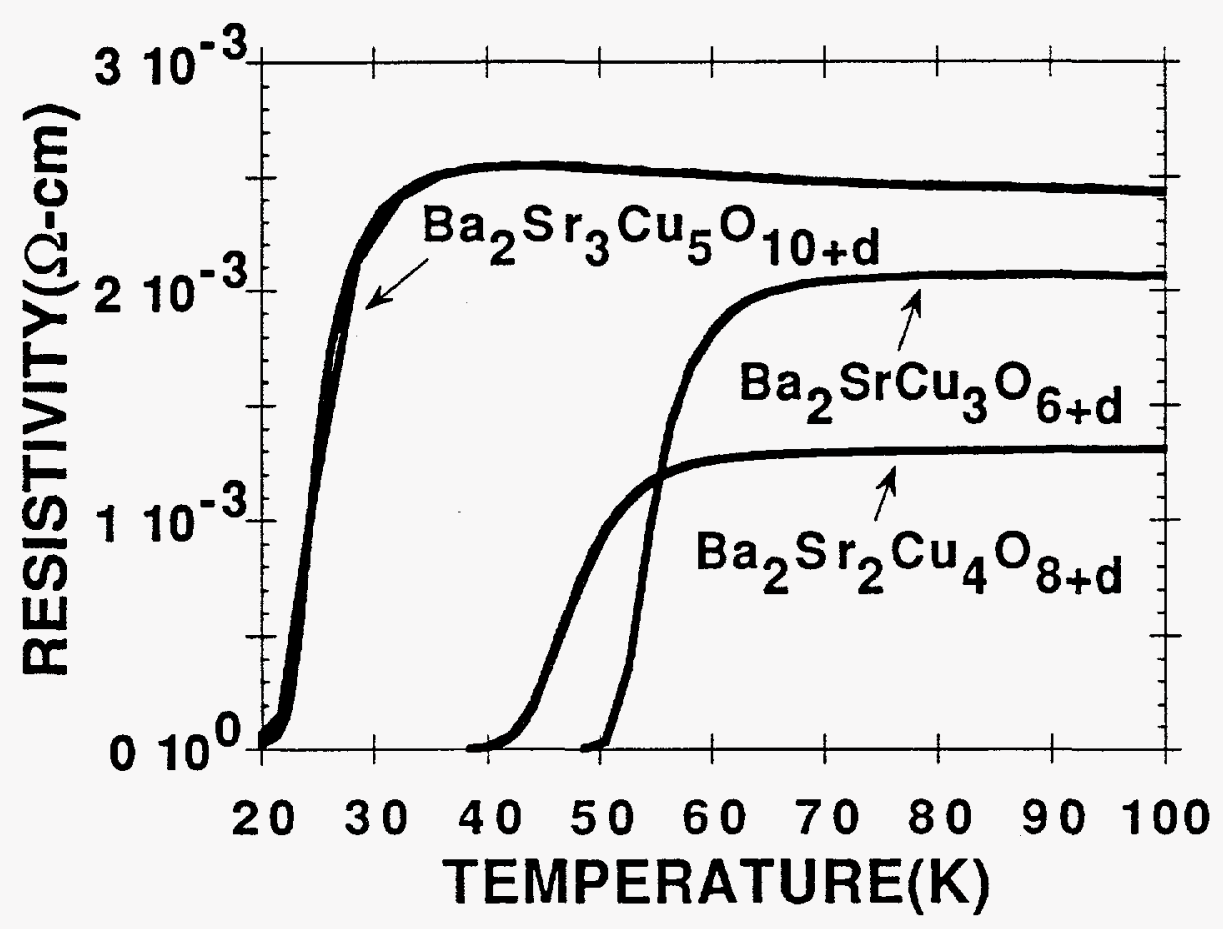

Fig. 7 Resistivity plotted as a function of temperature for the $n=2,3$, and 4 members of the $\mathrm{Ba}_{2} \mathrm{Sr}_{n-1} \mathrm{Cu}_{n+1} \mathrm{O}_{2 n+2+\delta}$ series.

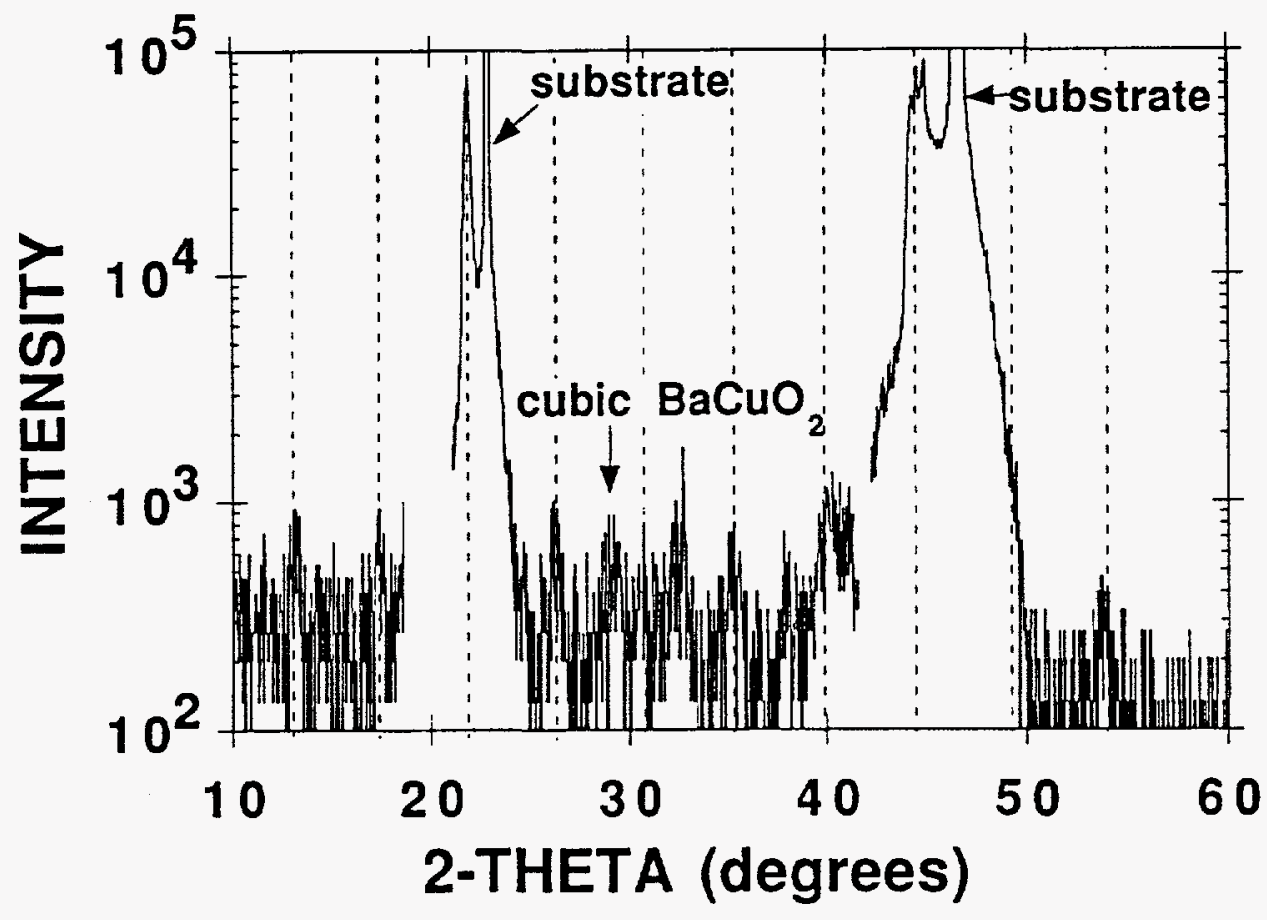

Fig. $8 \mathrm{X}$-ray diffraction pattern for a $\mathrm{SrTiO}_{3} / \mathrm{BaCuO}_{2}$ superlattice with a superlattice periodicity of $20.4 \AA$. The dashed lines indicate the expected locations for the superlattice diffraction peaks. Note that a small amount of cubic $\mathrm{BaCuO}_{2}$ is present in this film as an impurity phase. 
stabilized in the infinite layer structure. In addition, superlattice satellite peaks are evident as well. While superconductivity has not been observed in these structures to dates, the resistivity is significantly lower than that of $\mathrm{SrTiO}_{3}$ or cubic $\mathrm{BaCuO}_{2}$. The ability to epitaxially stabilize $\mathrm{BaCuO}_{2}$ in the infinite layer structure using $\mathrm{SrTiO}_{3}$ may provide a means of studying the intrinsic transport properties of this material, as $\mathrm{SrTiO}_{3}$ is an excellent insulator.

\section{CONCLUSION}

In conclusion, we have grown infinite layer $\mathrm{SrCuO}_{2} /(\mathrm{Ca}, \mathrm{Sr}) \mathrm{CuO}_{2}, \mathrm{SrCuO}_{2} / \mathrm{BaCuO}_{2}$, as well as $\mathrm{SrTiO}_{3} / \mathrm{BaCuO}_{2}$ superlattice structures using conventional pulsed-laser deposition. X-ray diffraction reveals peaks due to the superlattice chemical modulation, even for structures with layers as thin as a single infinite layer unit cell $(-3.4 \AA)$. The $x$-ray diffraction data also show intensity oscillations due to the finite thickness of the film, indicating extremely flat film surfaces with thickness variations of only $20 \AA$ over a length scale of several thousand angstroms. $\mathrm{SrCuO}_{2} / \mathrm{BaCuO}_{2}$ superlattices in the infinite layer structure represent novel artificially-layered superconducting thin-film compounds. These results represent not only the synthesis of new families of superconductors, but also demonstrate that pulsed-laser deposition and epitaxial stabilization can be effectively used to engineer artificially-layered thin-film materials.

\section{REFERENCES}

1. J. G. Bednorz and K. A. Muller, Z. Phys. B, Cond. Matter. 64, 189 (1986).

2. T. A. Vanderah, Chemistry of Superconductor Materials, Noyes Publications (Park Ridge, N. J., 1992).

3. A. Schilling, M. Cantoni, J. D. Guo, H. R. Ott, Nature 363, 56 (1993).

4. H. Ihara et al., Jpn. J. Appl. Phys. 33, L503 (1994).

5. C. -Q. Jin, S. Adachi, X.-J. Wu, H. Yamauchi, S. Tanaka, Physica C 223, 238 (1994).

6. M. A. Alario-Franco, C. Chaillout, J. J. Capponi, J.-L. Thoulence, B. Souletie, Physica C 222, 52 (1994).

7. Z. Hiroi, M. Takano, M. Azuma, Y. Takeda, Nature 364, 315 (1993).

8. J. N. Eckstein et al., Appl. Phys. Lett. 57, 931 (1990).

9. T. Terashima et al., Phys. Rev. Lett. 60, 3045 (1992).

10. M. Y. Chern, A. Gupta, B. W. Hussey, Appl. Phys. Lett. 60, 3045 (1992).

11. D. P. Norton, B. C. Chakoumakos, J. D. Budai, D. H. Lowndes, Appl. Phys. Lett. 62, 1679 (1993).

12. C. Niu and C. M. Lieber, J. Am. Chem. Soc. 114, 3570 (1992).

13. M. Yoshimoto, H. Nagata, J. Gong, H. Ohkubo, H. Koinuma, Physica C 185, 2085 (1991).

14. M. Kanai, T. Kawai, S. Kawai, Appl. Phys. Lett. 58, 771 (1991).

15. T. Siegrist, S. M. Zahurak, D. W. Murphy, R. S. Roth, Nature 334, 231 (1988).

16. M. G. Smith, A. Manthiram, J. Zhou, J. B. Goodenough, and J. J. Markert, Nature 351, 549 (1991).

17. G. Er, Y. Miyamoto, F. Kanamaru, and S. Kikkawa, Physica C 181, 206 (1991).

18. M. Takano, M. Azuma, Z. Hiroi, Y. Bando, and Y. Takeda, Physica C 176, 441 (1991).

19. Z. Hiroi, M. Takano, M. Azuma, Y. Takeda, and Y. Bando, Physica $C$ 185-189, 523 (1991).

20. M. Azuma, Z. Hiroi, M. Takano, Y. Bando, and Y. Takeda, Nature 356, 775 (1992).

21. M. Takano, Y. Takeda, H. Okada, M. Miyamoto, and K. Kusaka, Physica C 159, 375 (1989).

22. X. Li, M. Kanai, T. Kawai, and S. Kawai, Jpn. J. Appl. Phys. 31, L217 (1992).

23. X. Li, T. Kawai, and S. Kawai, Jpn. J. Appl. Phys. 31, L934 (1992).

24. K. Kobayashi, Y. Ishihara, S. Matsushima, and G. Okada, Jpn. J. Appl. Phys. 30, L1931 (1991).

25. Y. Terashima, R. Sato, S. Takeno, S. Nakamura, and T. Miura, Jpn. J. Appl. Phys. 32, L48 (1993). 
26. S. Takeno, S. Nakamura, Y. Terashima, and T. Miura, Physica C 206, 75 (1993).

27. N. Terada, G. Zouganelis, M. Jo, M. Hirabayashi, K. Kaneko, and H. Ihara, Physica C 185-189, 2019 (1991).

28. D. P. Norton, B. C. Chakoumakos, E. C. Jones, D. K. Christen, and D. H. Lowndes, Physica C 217, 146 (1993).

29. D. P. Norton, J. D. Budai, D. H. Lowndes, and B. C. Chakoumakos, Appl. Phys. Lett. 65, 2869 (1994).

30. D. P. Norton, B. C. Chakoumakos, J. D. Budai, D. H. Lowndes, B. C. Sales, J. R. Thompson, and D. K. Christen, Science 265, 2074 (1994).

31. O. Nakamura, E. Fullerton, J. Guimpel, and I. Schuller, Appl. Phys. Lett. 60, 120 (1992). 